\section{Commentary: Why do uniportal video-assisted thoracoscopic lobectomy?}

\author{
Rafael Andrade, MD, MHA
}

In this issue of the Journal, Ugalde and colleagues ${ }^{1}$ present a careful learning curve analysis of a very large singlesurgeon experience with uniportal video-assisted thoracoscopic (U-VATS) lobectomy. The authors used operative time and conversion to thoracotomy or multiport VATS as key outcome metrics to gauge their proficiency. Their findings indicate that $60 \mathrm{U}$-VATS lobectomies were needed to complete the initial phase of the learning curve, and an additional 80 U-VATS lobectomies (ie, a total of 140) were required to become proficient.

These findings support the recommendation of the Uniportal VATS Interest Group (UVIG) of the European Society of Thoracic Surgeons (ESTS) that 50 is the cutoff number of cases to overcome the learning curve. $^{2}$ Although 60 seems like a reasonable number of cases to get comfortable with a complex procedure, we cannot underestimate the technical challenge of U-VATS lobectomy. The authors work in a highvolume center and already had extensive experience with 2-port VATS lobectomy, and even then they required 60 cases to get comfortable with U-VATS lobectomy. U-VATS lobectomy is not easy to learn even for experienced multiport VATS surgeons, given the differences in vantage point and instrument handling. U-VATS requires that surgeons take the unnerving step of leaving their comfort zone and becoming novices at something again. ${ }^{3}$

Why do U-VATS lobectomy? We probably can safely assume that U-VATS and multiport VATS lobectomy are oncologically equivalent when performed properly, and that the postoperative recovery from the 2 approaches is similar. It seems unlikely that a clinical trial of U-VATS lobectomy versus multiport VATS lobectomy

From the Division of Thoracic and Foregut Surgery, University of Minnesota, Minneapolis, Minn.

Disclosures: Author has nothing to disclose with regard to commercial support.

Received for publication Nov 15, 2019; revisions received Nov 15, 2019; accepted for publication Nov 15, 2019; available ahead of print Feb 6, 2020.

Address for reprints: Rafael Andrade, MD, MHA, Division of Thoracic and Foregut Surgery, 420 Delaware St SE, MMC 207, Minneapolis, MN 55455 (E-mail: andr0119@umn.edu).

J Thorac Cardiovasc Surg 2020;159:2496

$0022-5223 / \$ 36.00$

Copyright (c) 2019 by The American Association for Thoracic Surgery

https://doi.org/10.1016/j.jtcvs.2019.11.081

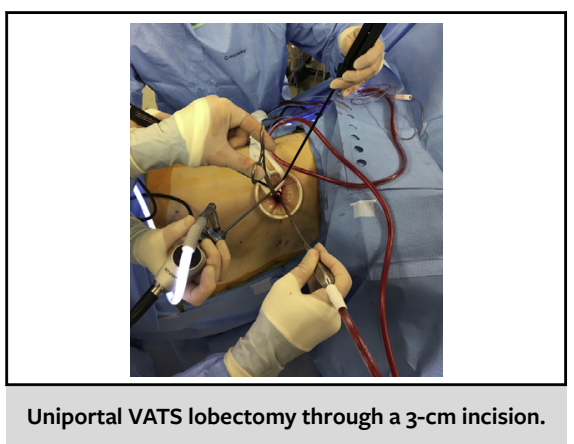

CENTRAL MESSAGE

Why do a uniportal VATS lobectomy? Because embracing chal-

lenges is the only way to grow.

would demonstrate a significant difference in operative outcomes.

Assuming that U-VATS doesn't offer a measurable benefit to patients, why bother? Because innovation is a stepwise process and every step begets further steps to reach an as-yet unimaginable goal. ${ }^{4}$ For instance, what would have Dr Evarts A. Graham thought in 1933 if someone had told him that pneumonectomy would be performed via VATS? At that time, this approach would have been inconceivable, and even in the 1980s, VATS anatomic resections were still considered an impossibility. But now we do U-VATS complex sleeve resections and pneumonectomies. What happened in the intervening $7 \mathrm{de}-$ cades? People chose to leave their comfort zones and to take incremental steps.

Individuals who embrace challenges are indispensable agents of change. Incremental steps, such as the development of staplers, muscle-sparing incisions, further development of scopes and instruments, and advances in anesthetic techniques, have made U-VATS anatomic lung resections feasible. Each individual step may seem small, but the additive effect over time can be transformative.

U-VATS lobectomy is yet another incremental step in the evolution of thoracic surgery and we cannot predict where it will eventually lead us. A surgeon skilled in U-VATS could be poised to perform subxiphoid and transcervical lung resection and maybe even natural orifice (NOTES) lung resection. This may seem inconceivable now, but so did U-VATS pneumonectomy in 1933. Leaving our comfort zones is the only way to grow. 


\section{References}

1. Vieira A, Bourdages-Pageau E, Kennedy K, Ugalde PA. The learning curve on uniportal video-assisted thoracic surgery: an analysis of proficiency. J Thorac Cardiovasc Surg. 2020;159:2487-95.e2.

2. Bertolaccini L, Batirel H, Brunelli A, Gonzalez-Rivas D, Ismail M, Ucar AM, et al. Uniportal video-assisted thoracic surgery lobectomy: a consensus report from the Uniportal VATS Interest Group (UVIG) of the European Society of Thoracic Surgeons (ESTS). Eur J Cardiothorac Surg. 2019;56:224-9.

3. Andersen E. Learning to learn. Harv Bus Rev. 2016;94:98-101.

4. Andrade R, Bhargava A. No pain, no gain. Eur J Cardiothorac Surg. 2018;54 969-70.
See Article page 2487.

\section{Commentary: See one, do one, teach one...not anymore}

\author{
Lisa M. Brown, MD, MAS, FACS
}

"See one, do one, teach one" is a time-honored phrase of surgical education that is familiar to us all. This was a common approach to surgical education but is no longer relevant as technology has become more advanced, leading us to begin to perform complex operations via minimally invasive approaches. Certainly, a better approach to teaching trainees is to have them do portions of these operations, increasing as they progress and to provide opportunities for simulation in preparation for the operation. Furthermore, throughout the course of our own careers, new techniques, technology, and approaches will be introduced, ones that we had not encountered in training. As surgeons, we need to take a thoughtful, well-planned, and data-driven approach to incorporating changes into the way we conduct operations, which is exactly what Vieira and colleagues ${ }^{1} \mathrm{did}$ to transition to the uniportal video-assisted thoracic surgery (VATS) approach for lung resections.

The cardiothoracic surgical literature is full of articles on "How I Do It" and "How I Teach It," but few and far between are the articles on "How I Learned It" authored by a surgeon who is already in expert in the field who is willing to provide transparency on his or her personal learning curve. That is what "The learning curve of uniportal

\footnotetext{
From the Section of General Thoracic Surgery, University of California, Davis Health, Sacramento, Calif.

Disclosures: Author has nothing to disclose with regard to commercial support.

Received for publication Nov 10, 2019; accepted for publication Nov 12, 2019; available ahead of print Jan 24, 2020.

Address for reprints: Lisa M. Brown, MD, MAS, FACS, University of California, Davis Health, North Addition Office Building, 2335 Stockton Blvd, Room 6122, Sacramento, CA 95814 (E-mail: Imbrown@ucdavis.edu)

J Thorac Cardiovasc Surg 2020;159:2497-8

0022-5223/\$36.00

Copyright (c) 2019 by The American Association for Thoracic Surgery

https://doi.org/10.1016/j.jtcvs.2019.11.047
}

Check for updates

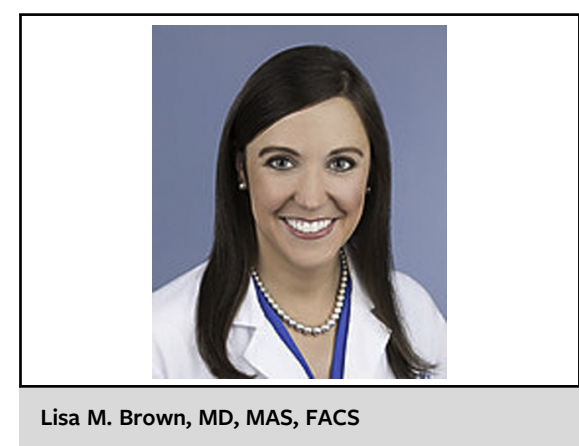

CENTRAL MESSAGE

Adopting the uniportal VATS

approach should be planned and

data driven to achieve proficiency while maintaining safety

and adherence to oncologic

standards.

video-assisted thoracic surgery: an analysis of proficiency" provides to the Journal's readership.

The uniportal VATS technique was first described by Rocco in $2004^{2}$ and, in 2011, the first uniportal VATS lobectomy was reported by Gonzalez-Rivas and collegues. ${ }^{3}$ A systematic review and meta-analysis of uniportal versus multiportal VATS lobectomy identified a statistically significant reduction in complications, length of stay, and duration of chest tube drainage for those undergoing uniportal VATS. ${ }^{4}$ There was no difference in mortality, operative time, perioperative blood loss, and conversion to thoracotomy between the 2 groups. ${ }^{4}$ In this issue of the Journal, Vieira and colleagues ${ }^{1}$ provide details on a 4-year learning curve for uniportal VATS. Highlights of their learning curve process are the following: (1) Prospective database of uniportal VATS cases including clinical and operative details as well as videos, (2) ongoing review of cases after each 20, and (3) the development of a standard approach for each lobe. The authors used rigorous statistical methods to determine the learning curve phases (initial, transition, and proficient) and 